\title{
Strategy as Practice: An Organizational Culture Approach in a Higher Education Institution in Kosovo
}

\author{
Hajdin Berisha \\ PhD Candidate, Department of Business Administration, \\ Marmara University, Turkey \\ Corresponding Author \\ Saxhide Mustafa \\ PhD Candidate, Department of Management, \\ University of Tirana, Albania \\ Yusof Ismail \\ Lecturer, Department of Business Administration, \\ IIUM, Malaysia
}

Doi: 10.2478/jesr-2018-0029

\section{Abstract}

Organizational members perceive top management as the sole authority for strategy making. Whilst this has been true for a number of years, the last decade has provided a shift to this traditional strategy practice in some sectors in the society. This paper attempts to address two major questions: firstly, whether the classical view of strategy as a property of organizations and the sole responsibility of top management in strategy making holds true in one of the higher education institutions in Kosovo as a member of western Balkan and eastern European countries. Secondly, how top management influences strategy practices of sense-making and sense-giving through organizational culture. The research analyses organizational culture and its effect on strategy as practice before and after a shift of institution's top management based on its six strategy dimensions. The study employs multiple sources of data to address the research questions: secondary sources, semi-structured interviews, informal discussions with institution's staff members, two-week of shadowing, observations and viewing artefacts of the institution. Results reveal three threads: organizational culture plays an important role on strategy as practice; top management is perceived to primarily provide sense through face-to-face interaction and procedural measures of strategy practices; and staff members are mostly involved in implementation. Moreover, clan and hierarchical types of organizational culture are identified to shape strategy practices of the institution. The study suggests that while the strategy making practice should be at the core of institution, a pleasant and non-confronting organizational culture is crucial to attract new students and retain elite staff.

Keywords: Strategy, Practice, Culture, Organizations, Higher Education

\section{Introduction}

The pre-conceived view that strategy is a property of organizations has been dominant for years among organizations, researchers and practitioners. This traditional understanding has mainly viewed strategy as an asset that organizations have (Jarzabkowski, 2005; Whittington, 2006). With the new developments among researchers in the field of strategy, the notion of strategy as a 
property has shifted to strategy as an activity which organizations perform. This in particular is the concern of strategy as practice (SAP) as a relatively emerging field among some researchers (Jarzabkowski, 2005; Whittington, 2006; Chia and MacKay, 2007).With this thread, the strategy is no longer viewed as organizational property - something that organizations have, but what in fact organizations and their members do in the making of strategy and how their members shape strategy practices.

As a response to these developments, Strategy as Practice (SAP) grew and as the literature in this field suggests, the last decade in particular has triggered great research interests and agendas among academics and organizational practitioners. This paper provides additional input into existing body of knowledge in SAP field.

With Whittington (1996) as the main architect of this view who for the first time suggested the three building blocks, i.e., practices, praxis and practitioners, the field has triggered serious interests among researchers, academics, organizations and practitioners. Despite gaining momentum for almost two decades however, the view that strategy is something organizations have and the making of strategy is primarily the responsibility of top management and of the CEO in particular is still dominating. Although the vast majority of research in Strategy as Practice have been focused mainly on for profit organizations, in recent years academic institutions such as universities have been targeted as a significant source of research in SAP (Jarzabkowski, 2005). It is in this light that the focus of this research is directed to an academic institution.

This paper is organized according to the following structure structure: The first part provides logical and practical grounds of SAP research in academic institutions. A brief background of the institution involved in this research is also offered to readers. The second part analyses the existing body of knowledge in the field of Strategy as Practice. In particular, it focuses on evolution of SAP followed by its development through time, contemporary research agenda, benefits, advantages and critiques that SAP has brought to the field of strategic management. The third section explains the methods employed in this study. The fourth part discusses findings of the research while the last section concludes and recommends future research avenues. To preserve anonymity, the institution's name is disguised. Instead, institution is referred to either as HEl or/and institution throughout the paper.

\subsection{SAP research and its importance in the context of Kosovo}

Researches with regards to Strategy as Practice in Kosovo are almost non-existent. Researches to identify strategy making practices and how organizational members shape the strategy making in academic institutions have been neglected by academics and researchers. A research of this kind has certainly not been carried out at the institution selected for the study. Hence, the research will be the first of this type at the institution and perhaps in the country also.

The study expects to contribute by revealing the role of strategy as practice in an academic institution. In this context, the research provides significant contribution that will enable future researchers to view the strategy making process not solely a responsibility of top management but also identify the importance of other practitioners' involvement and the impact of organizational culture in strategy practice. The research strives to provide significant findings to management of the institution that perhaps were uncovered to date. While the current study is focused on an institution, its findings may spur further research interests in other organizational types and in different countries.

\subsection{Rationality and practicality of sap research at HEI}

There are three primarily logical and practical reasons for selecting this institution to conduct SAP research.

First, two researchers have been part of the institution for several years. They have held various managerial and administrative positions at the institution and are well aware of strategy practices and organizational culture at the institution.

Second, availability of data. Researchers have obtained top management's consent to 
conduct SAP research at the institution. In particular, researchers had discussed with one of the main founders of the institution about their research interest in SAP and the material that were needed therein. The founding member highly appreciated the research intent and expressed his great readiness to support researchers with any information needed.

Researchers have also discussed with key members who have served at this institution for over a decade. One of the key personnel included an officer who had access to all materials such as minutes of meetings of board of directors, the existing three-year strategic plan of the institution and all other data necessary to conduct SAP research.

Finally, as the institution has a well-established strategy making process and strategic plan which serve as official plans and directive measures of the institution's operations, it enriched the reliability and validity of the findings of the research. Competition among education providers in Kosovo is tense. The institution concerned in this research is aware of this and pays great attention to strategy making practices for its operations.

\subsection{A brief historical context of higher education institution}

The HEI was established in 2007 with its headquarters in capital city of Kosovo, Prishtina. With the mission to provide education mainly in the field of economics and information technology and promote modern economic development research for Kosovo, the HEI was licensed by the Ministry of Education, Science Technology. The goal was to offer programmes that would develop skills that will link with the economy, business and information technology.

The HEl currently offers Bachelor and Master programmes in Albanian Language, and BA and MBA programmes in English Language under an agreement with an international university.

As a private higher education provider, the HEl is governed in accordance with the business law and law on higher education of the country. The highest academic body of HEI is Academic Council, while the Board has the responsibility to appoint, govern, and oversee the Chief Executive Director (rector) of the institution.

\section{Literature Review}

\subsection{Chronological development of strategy as practice}

Prior to 1970s discussions about Strategy as an academic subject were almost non-existent. According to Johnson et al. (2007), it was in 1970s that strategy appeared in literature while two years later (1972) journals such as Strategic Management Journal became popular among academics. However, the main stream strategy has contended that strategy is to be developed by top management through formal hierarchical structures and be implemented through the top-down approach. Thus, despite the long standing that the traditional view has been around (and perhaps it is still dominant in some organizations), the literature on strategic management implied that a more practice-based approach was required (Johnson et al., 2007). Although the question of what managers do was discussed by Henry Mintzberg (1973), Vaara, and Whittington (2012) argue that origins of SAP could be traced back to the work of Whittington (1951) and Heidegger (1962).

Maia, Serio and Alvesfllho (2015) are of the opinion that two decades ago research on SAP was conducted under sociological approach of strategy. According to them, Richard Whittington's paper entitled "Strategy as Practice (1996)" laid the foundations of the study of SAP which later triggered interests of various researchers, academics, scholars and organizational members mainly but not limited to the field of management and strategic management.

Whilst Jarzabkowski, Balogun and Seidl (2007) contend that the need for SAP research arose as research on strategy seemed to lose sight of human being, for Maia, Serio and AlvesFillho (2015) challenging the traditional approach which merely treated strategy as a property of organizations was the underpinning reason of SAP research development.

Following the great interest among academics, Varyani and Khammarah (2010) note that various workshops were organized whilst in 2003 a special issue about SAP was released (Maia et al. 2015). 
Among all the early scholars, contributors, advocates and academics, the literature suggests that Paula Jarzabkowski and Richard Whittington are the pioneers and most productive authors in the field of SAP (Maia et al. 2015). Similarly Varyani and Khammar (2010) are of the opinion that Richard Whittington, Paula Jarzabkowski and Gerry Johnson are the first to have introduced the new concept of Strategy as Practice, whereas Whittington (2006) proposed the first model which consists of praxis, practices and practitioners as three interrelated concepts as shown in Figure 1 below:

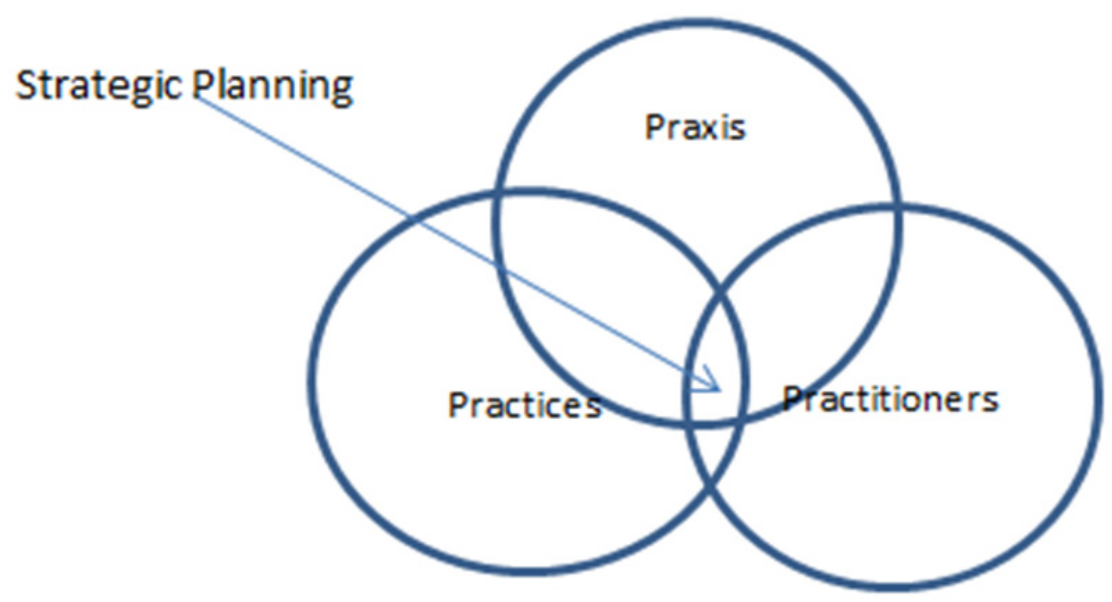

Figure 1: Praxis, Practices and Practitioners

Source: Whittington (2006)

\subsection{Contemporary research interest on strategy as practice}

The area of Strategy as Practice has triggered great interest among researchers with a virtual community of over 2,000 members, widespread conferences, the official website and an increasing number of publications in well-known journals (Jarzabkowski, Balogun and Seidl, 2007). To analyse developments of research publications in the field of SAP, Maia, Serio, and Alvesfllho (2015) conducted a Bibliometric research in Web Science and Google Scholar. In analysing authors and institutions carrying research and publications in the field of SAP, they revealed that five authors cover nearly half of all publications. Among all countries, UK appeared to be at the top of the list of countries in SAP research (Maia, Serio, and Alvesfllho, 2015).

While SAP has received a great deal of interest among academics in the past decade, it is still considered to be a new and young field with most of the research (92\%) being published after 2007 (Varyani and Khammarah, 2010; Maia et al. 2015). Hence, as the field is still under consolidation and development, Jarzabkowski (2005) argues that more research needs to be carried out, and in universities in particular.

\subsection{How to research on strategy as practice?}

In general, Strategy as Practice can be researched from various angles and perspectives. Johnson, et al. (2007) emphasize that the best way is through observation as they refer to "go out and look". Alternatively researchers may rely on their own experience while undoubtedly qualitative data are essential in developing the SAP research. To date, a number of researchers have researched SAP field from various perspectives. Fredericks (2003), for example, conducted a research on strategizing as a lived experience as opposed to a reported experience during interviews. Similarly, Bürgi, Jacobs and Roos (2005) conducted a research at a large telecommunications firm to explore 
how the link between the hand and the mind might be exploited in strategy formulation. While arguing that institutions can no longer craft strategies by trial and error, they concluded that if hands are placed in all kinds of organizational learning, new ways of strategy making process may be achieved.

Heracleous and Jacobs (2008), on the other hand, found how metaphors can serve as appealing events for sense making in strategy making process. They suggest that metaphors are effective tools that can help managers discuss various strategic matters. Likewise, Fento and Langley (2008) through analysing strategy making process using narratives provided interesting results. Their findings correspond with Boje (1991) for whom storytelling is a skill which managers can use to influence others to act in certain and desired ways.

\subsection{Special features and benefits of strategy as practice}

Vaara and Whittington (2012) argue that SAP research has provided four main distinctive benefits: first, it has drawn on sociological rather than economic theories of practice; second, it has widened the scope of what strategy research explains; third, it has expanded the types of organizations studied; and fourth, it has increased research methodologies. Looking at the impact of employee involvement on staff motivation, Burig, Roos and Jacobs (2001) indicate that the process of developing strategy can offer passion to employees.

\subsection{Critiques and challenges of strategy as practice}

The research in Strategy as Practice seems not to be evolved unchallenged. Jarzabkowski, Balogun and Seidl (2007), note that despite its great achievements, several challenges to develop SAP into a robust field of research still exist. In this regard, the gap between theories of what strategy is and its actual practice is a problem with which academics are faced (Jarzabkowski, 2005).

A decade later, Jarzabkowski et al. (2015), argued that it is necessary to consider how effects of practice are linked with practitioners' effects. They indicated that as a same practice may have different performance outcomes depending by whom they are introduced and the context in which they operate, not only what practices exist but who and how they are executed should also be considered. Hence, it is risky to consider practices in isolation without considering the contextual environment of their development and those who implement them (Jarzabkowski et al.2015).

\section{Research Methodology}

The vast majority of researchers have employed qualitative approaches to research Strategy as Practice. Since the subject of the research is HEl's staff members and their practices, this research also employs a qualitative approach. Bryman and Bell (2007) point out that qualitative approach of research is proposed when relatively little is known about a field of study or when a new viewpoint is researched. According to them, instead of focusing on quantifications and frequencies, qualitative research focuses on interpretations. Through a qualitative approach this study collected data for a four year period (2013-2017), more than three years (2013-2016) of which were retrospective and less than one year were real time.

Among relatively a large number of HEls operating in Kosovo, this study focuses solely at one HEI particularly focusing on its six strategic dimensions (See Figure 2): 


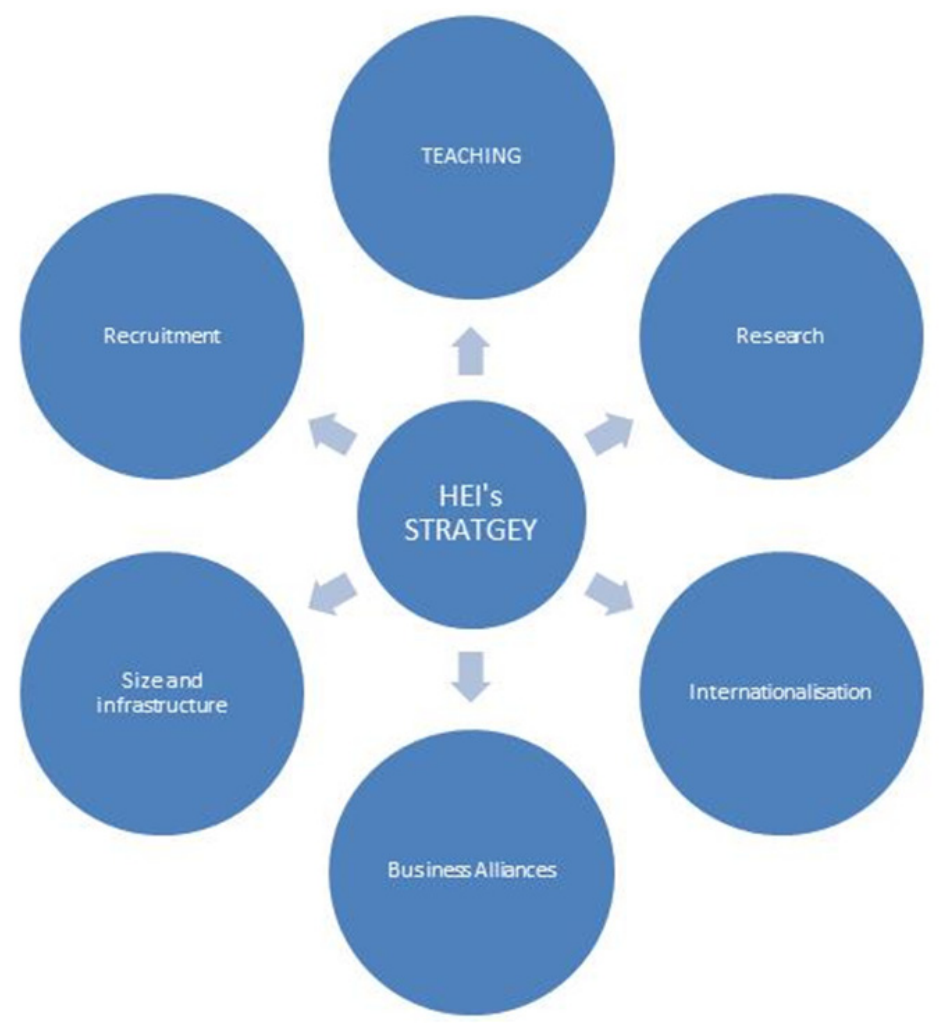

Figure 2: Dimensions of HEl's Strategy

Source: Compiled by authors

\subsection{Sampling and data collection methods}

According to Patton (2002) and Miles and Huberman (2003), in general three principles are important for sampling in qualitative research. First, sampling instead of being random or probabilistic should be purposeful. Second, to understand the unit, researcher should collect information from as many sources as possible. Third, researcher should strive to provide comparisons between sampling units.

To collect data, researchers drew on their own experience as members of the $\mathrm{HEI}$, observation, artefacts of the institution, semi-structured interviews and multiple secondary sources such as HEl'S strategic plan, minutes of meetings of board of directors, minutes of meetings of academic councils, reports, etc.

\subsection{Interviews}

According to Bryman and Bell (2007), interviewing is the most widespread method for data collection in qualitative research. This study employs semi-structured interviews. Bryman and Bell (2007) defined semi-structured interviews as a method which enables the interviewee to speak freely while questions serve as the instrument to keep the flow of the interview.

A set of 10 interview questions were prepared by researchers. The perspective of every interviewee was traced using these interview questions. Interviews began by asking the interviewees about their understanding of the strategy. For comfortability, interviews were conducted in the interviewees' own offices. In addition, formal interviews also included discussions 
over coffee, lunch time and attending workshops and meetings. For example, one member of board of directors preferred to be interviewed during lunch time rather than at his own office.

Interviewees were assured that no one else will have access to the transcripts and that the research is only for academic purposes. The consent of the interviewees was obtained by signing the interview consent form.

Two rules were applied in particular for interviews: The 24-hour rule which required that detailed interview notes be completed within one day of the interview. The second rule was to include all data, regardless of the importance at the time of the interview. Researchers noted every detail of the discussion whilst with interviewees' request interviews were not recorded using electronic recorder.

Each interview lasted between 20 to 40 minutes. Overall, a total of seven (7) interviews were conducted with various members who were identified through organizational structure of the $\mathrm{HEI}$. The composition of interviewees is shown in the table below:

Table 1: Composition of Interviewees

\begin{tabular}{|clc|}
\hline No & Source & Frequency \\
\hline $\mathbf{1}$ & Members of Board of Directors & 2 \\
\hline $\mathbf{2}$ & President of Academic Council & 1 \\
\hline $\mathbf{4}$ & Director of Operations & 1 \\
\hline $\mathbf{5}$ & Head of Departments & 2 \\
\hline $\mathbf{6}$ & Head of Recruitment Office & 1 \\
\hline & Total & $\mathbf{7}$ \\
\hline
\end{tabular}

\subsection{Secondary sources}

Interviews were supplemented with secondary sources as depicted in Table 2 below. The research paid a great deal of attention in the strategy practices of the new CEO who almost immediately after his arrival (in 2016) launched a major strategic change effort with the goal of making the institution into what he called "the best university in Kosovo".

Although he did not present any strategic plan upon his arrival as the existing three-year (2015-2018) strategic plan was in force until 2018, some significant strategic initiatives have taken place under his tenure. The sources below (see Table 2) are used to analyse HEl's strategic dimensions:

Table 2: Secondary Data sources

\begin{tabular}{|c|l|}
\hline No & Source \\
\hline $\mathbf{1}$ & HEl's Status Document (1) \\
\hline $\mathbf{2}$ & HEl's Strategic Plan (2015-2018) \\
\hline $\mathbf{3}$ & Minutes of Board Meetings (2013 through 2017) \\
\hline $\mathbf{4}$ & Minutes of Academic Council Meetings (2013 through 2017) \\
\hline $\mathbf{5}$ & Minutes of Programme Committee Meetings (12) \\
\hline $\mathbf{6}$ & Strategic meetings with heads of departments (6) \\
\hline $\mathbf{7}$ & International Agreements and MoUs (7) \\
\hline $\mathbf{8}$ & Inter-university agreement (1) \\
\hline $\mathbf{9}$ & Academic databases \\
\hline $\mathbf{1 0}$ & HEl's Self Evaluation Report (latest 2014) \\
\hline $\mathbf{1 1}$ & HEl's calendars \\
\hline $\mathbf{1 2}$ & Briefing papers \\
\hline $\mathbf{1 3}$ & HEl's brochures \\
\hline
\end{tabular}




\section{Findings and Discussion}

Multiple sources of secondary data, conducted interviews and HEl's artefacts were attentively analysed in relation to the six dimensions of HEl's strategy practices. The following strategy practices were observed at the $\mathrm{HEl}$.

First, the preconceived view that strategy is a property that organizations have rather than an activity, in which organizational practitioners are involved in doing, tends to dominate at the HEl. Except two interviewees who came from strategic management background, others defined strategy either as a property or an asset of the university: "a plan that university has", "a useful abstract asset", "the main document that the university has", and "it is something that our university has and follows".

Second, the main responsibility of strategy making lies with the top management with limited involvement of other practitioners. Top management provides sense-making of strategy practices both through face-to-face interactions and formal administrative procedures as strategizing practices. "Questions 4-6 focused on the responsibility of strategy making. The most common answers were: "Top management", "of course top management", "senior management" and "higher level management".

Third, after a two-week observation and shadowing at the HEI and discussions with various staff members, it was observed that there is a sense among practitioners that at this point the HEI needs a clearer strategy.

Fourth, clan and hierarchical organizational culture tends to affect practices in strategy making process. The following discussion presents the findings over six dimensions of HEl's strategy practices.

\subsection{Teaching}

The HEI was observed to primarily maintain a teaching orientation while top managers involved themselves at the strategic level of quality. The three-year strategic plan and the latest selfevaluation report (2014) emphasize that its "education activities are student focused". Since its inception the $\mathrm{HEI}$ has strived to build a reputation over its competitors by providing high quality teaching standards. A strategic decision of the institution involved hiring the best possible staff members who possess local and international experience while ensuring that all teaching staff members speak a second language as stated in the HEl's brochure " $80 \%$ of our staff has an international degree or qualification".

Teaching strategy is dedicated to provide high quality studies and student progress is monitored closely as highlighted in one meeting by the founding member: "Student progress is regularly reviewed in Programme Committee Meetings and presented and approved in Academic Council". The academic planning unit and the regulation of $\mathrm{HEI}$ described two academic council meetings and four programme committee meetings in an academic year. To ensure greater quality of studies, the last strategy of the institution expects most instructors at Bachelor's level to be regular and internal lecturers, while at Master's level lecturers are mostly external, joining the HEI from industry and sharing their industrial expertise.

Unlike in the past where lecturers were paid hourly, the latest strategic practice expects lecturers to be paid a fixed monthly salary as described by the CEO: "We expect to empower our internal staff while maintaining satisfactory costs". However, in making this strategic plan, it was observed that staff members were not involved. In fact, decision was made by the top management, mainly CEO and CFO while head of Departments were asked to calculate the costs derived as a result, as one staff member said: "I was told by my boss that this is going to be my salary and this is my number of teaching hours I should complete: this is how they have decided. I do not know how they came about this decision".

Because of its high quality teaching standards, the HEI has been able to attract a relatively large a number of students to its programmes with particular focus in its business and MBA programmes which involve high-fee paying students and serve as an important source of income. However, the key strategic issue for management is maintaining the teaching quality while 
matching with its high delivery cost.

To enhance teaching quality a strategic decision which expects every module to involve a guest speaker from industry was developed. In a programme committee meeting, the head of academic planning unit emphasized: "Every lecturer should identify the date of guest speaker on the course outline". While the strategic decision of attendance monitoring process is observed, a decision which requires lecturers to strictly attend academic meetings was made. In one academic council the President emphasized " $10 \%$ of the salary reduction should be enforced for those who do not attend academic meetings". Hence, despite the face-to-face interaction as a strategizing practice, formal administrative practices were also found to shape the flow of strategy at the institution.

As a strategic supportive measure among staff members, the HEl observes a process called "peer observation" in which each lecturer is observed by his/her peer to share and enhance their expertise. In one strategic academic planning, the head of academic planning unit emphasized to heads of departments that "peer observation process should be practiced. We are in fact the only $\mathrm{HEl}$ in the country with this practice and we should be proud of it. I do not want this practice to be neglected".

During the study, researchers visited the institution to observe the artefacts of the HEI. The most appealing observation was that to enhance student motivation and create an academic environment, the $\mathrm{HEI}$ uses a practice of placing small academic quotes in the walls and corridors. For example, one quote said: "The aim of education is the knowledge, not of facts, but of values".

Overall, teaching strategy practices have focused on student needs while being committed to delivering a high class teaching and learning environment. The latest changes introduced by the new management have in general been positively welcomed by the staff members. Unlike previous management which put high trust on staff members (who in fact often did not accomplish their tasks) the new strategic initiatives have increased their responsibility and accountability. On the other hand, while under previous management, relations between top managers and departments were more pleasant and non-confrontational, the current situation has created more consciousness and competitive culture among staff members. Hence, it will be a strategic challenge for the management to attract new students and provide high teaching quality standards while maintaining elite staff and creating a friendly and pleasant working environment.

\subsection{Research}

Among all higher education providers, the HEI considers itself a leader within academic community in research activities. The research is organized and managed by its institute which provides sophisticated research database for staff and students.

A cautious observation was made how research activities with students were organized and then a discussion with one institute's researcher took place. He held the position of researcher who also was involved in teaching at bachelor's level. As part of a course assessment elements, he would invite interested students to participate in institute's research projects. Activities for first and second year students would mainly include distributing questionnaires, collecting data and finding potential respondents while third year students were involved in keying the data, using institute's database and software and to some extent, analysing the data. This practice has proved to be beneficial as the instructor said: "Students find it helpful and are very interested and active".

HEl's members also were constantly involved in important projects in developmental and economic oriented projects and local economic development strategies. HEl's strategic focus remained to establish a research fund through which staff and students' research activities will be funded. While increasing the quality of research performance in all departments was a key strategic issue for top managers, staff members were expected to dedicate "on average $40 \%$ of their working load to research activities" stated HEl's strategic plan. In this regard, however, in one occasion the founding member emphasized that the institution needs to put more effort in research through local and international conferences while providing opportunities for staff development through international agreements and collaboration. However, it was observed that overall, HEl's strategic orientation remains in teaching, attracting new students and retaining elite staff rather than research. 


\subsection{Size and infrastructure}

The HEl is currently located in a campus in capital city, Prishtina, with all necessary facilities which offer adequate opportunities for teaching, administration and student activities.

Developing facilities and infrastructure to meet the future needs of students was seen to be an important strategic issue for top management. With this goal in mind, immediately after his arrival, the new CEO started renovations of the physical appearance of the HEl. Among his first strategic steps was to change HEl's logo, followed by renovating almost the whole HEI, as the CEO said in one meeting: "We need to create an attractive environment for students". He even renovated the cafeteria to give it a different colour, appearance and image.

While changing some of the positions of the staff, he also changed their offices and made more technologically equipped meeting rooms. In his second meeting with staff members, CEO said: "Same field staff members are going to be allocated side by side to one another and no longer will students have to run from one office to another for a simple matter".

However, he emphasized "there is no strategic plan of expanding the university campus at a near future". His initiatives were welcomed by the HEI staff members while others were not aware about what was going on, as one staff member said: "There' s nothing left of this HEl except its name. Maybe they are going to change the name also. We have different logo and a more colourful university now. I am not sure how these colours will help us grow. I think we need students, not colours". However, the strategic initiatives are sought to have positively affected the HEI while the cultural power of involving practitioners in strategy making tends to increase gradually.

\subsection{Recruitment}

Competition within Higher Education providers remains stiff through price strategy which has resulted in student fees to be decreased by $15-30 \%$ on average in last five years. All public and private providers of Higher Education in Kosovo compete to attract on average some potential 20,000-25,000 applicants annually, apparently making most private providers seen as a second choice.

The HEl's strategy remains to attract potential students coming from middle income families, those from diaspora, students who have finished high schools in English Language with the aim to study at European universities, indicated the strategic plan.

To date, promotion strategies included mainly direct marketing, publicity in social media, open days and school visits. Current CEO has taken rigorous strategic moves in recruitment. As a first strategic initiative, he ensured that except for recruiting unit, other staff members should not be concerned about recruitment, as he indicated in one meeting with staff members: "The heads of departments and other members should not be concerned about recruitment. This will solely be the responsibility of recruitment office which will be established and empowered very soon".

While this has given some hope to staff members, it has created a sense of confusion of what is going to happen and how the HEl's recruitment strategy will be as one head of department said: "I am not sure if our student number will increase or what will happen. We will have to wait and see in October". Hence, unlike previously where it was a practice for all staff members to contribute in creating recruitment strategy, this has been transferred solely to the recruiting unit.

To attract a higher number of students, the CEO outsourced a marketing firm and hired a specialist of marketing as the head of recruitment office. Unlike previous strategic practices where advertisements on TV were not a strategic practice of the $\mathrm{HEI}$, now they have gained a crucial place of recruitment strategy, as the head of recruitment explained during the interview: "We will be rigorous in advertising on TVs". Recruitment office coordinates its activities directly with the CEO and the external firm while heads of departments are occasionally informed about the initiatives. In one occasion, the head of recruitment team sent an email to all staff members, including heads of departments to explain what she called "steps and procedures of new applicants coming to HEl". This strategic practice has created a sense and culture of top-down decision making approach where decisions are formulated at the top and staff is required to implement. 


\subsection{Business Alliances}

Collaborating with businesses is seriously seen as a strategic priority to the top management. Building a scholarship scheme within HEl's endowment in cooperation with some 60 important companies and other stakeholders is a priority for top management. The founding member declared that the "scholarship scheme will be used for subventions of teaching fee for best and talented students".

In the academic year 2016/17, through such collaboration the HEI has managed to secure 20 full scholarships for 20 first year students. As a strategic practice, the founding member initiated this idea through an email, which researchers had access to. The email was sent to key staff members who potentially had close relationships with businesses. Each staff member was required to discuss with two businesses and potentially secure two scholarships.

The strategic plan of the HEl explicitly states the importance of such collaborations that "HEI will continue to develop communication with businesses, governmental institutions, communities, civil society and media".

\subsection{Internationalisation}

As a practice, all HEl's international activities are mainly initiated and managed by the head of Academic Planning and International Affairs office in coordination with the CEO and to some extent with the founding member while other practitioners' involvement is seen in the implementation part.

It is at the heart of strategic plan of the HEl to offer students with opportunities for internships, practice at businesses, participation in research and other services while teaching will continue to be supported by international textbooks, cites the strategic plan of the HEI. From 2009, the HEI has been validated to offer programmes of a British university in the field of business management in bachelor's level, and from 2012 for MBA programmes. The strategic plan indicated that "by 2018 at least $10-15 \%$ of graduating students will have an international experience". However, the cultural practice that such activities should be managed by a particular person was observed to be a concern.

\subsection{Strategy practices and organizational culture from old to new management}

Since its establishment, it was a practice at the HEl that the founder as one of the main shareholders of the HEl to be the main person to run the HEl as one staff member confirmed: "he is the main person here". Although he has grown the HEl to the point that perhaps none of the management members would have done and has created a friendly environment where academic freedom was the core value, the strategy practices were seen by the staff members to derive mainly from top management.

The strategic practices as well as decisions mainly originated from him. For almost everything staff members had to discuss with him prior to any further development, as one staff said: "I can see certain individuals at the top management have the influence... I think in here, the culture also plays an important role. If one member is important, people wait for him to do things and tell others what to do". Although he was extremely cooperative, created a friendly environment, held the HEI together by loyalty and tradition but due to the power he had at the HEI and his seniority, it was a practice for staff to consult him.

The new management took office in November 2016. The CEO who is responsible for the business operations of the $\mathrm{HEl}$ and who comes from a business background with no experience in academic field exerted a different type of strategy practices and organizational culture. Upon his arrival, at the first meeting with HEl's members he introduced himself very shortly with no presentation of any forthcoming strategic plan. He then started to hold meetings with every staff member individually, seeking to understand problems that the $\mathrm{HEI}$ is facing. Following these meetings, the next strategic move was to create the structural hierarchy of the HEI. With a business mind set, he wanted to be clear on who is doing what. In so doing, he appointed heads of departments and other important units, such as recruitment office, academic planning office, and 
quality assurance office and made clear of their roles, responsibilities and expectations. Thus, he wanted a clear line of responsibility.

Coming from a business field, he was also particularly concerned about costs. As such, his strategic move was to fire an administrator and merged the administrator of bachelor's and master's levels in economics department (the core programme and the main contributor to HEl's income) into one.

Staff reshuffle was then followed by drastic changes in finance department. The CEO brought his own Finance Director with new software which required new human skills for which the HEI outsourced a company to train the finance staff members. The underpinning goal was to ensure collection of student tuition fees on time.

While all these strategic practices led to a better control of operations, they created a sense of confusion, cynicism and a hierarchical type of organizational culture where academic freedom as the core value began diminishing - something that was not common at the HEI under previous leadership. In such an environment, while changes were welcomed by majority of staff members, demotivation increased, as one employee put it: "There is nothing left to work for this HEl anymore. We don't have the joy as we had." Another staff said: "I am searching for another job; in fact I have already applied". Although staff did not resist such changes, however, the new organizational culture concerned with hierarchical positions seemed to provide highly controversial strategy practices.

\section{Research Constraints}

Obviously this research is not envisaged to be the only and the last. Despite its noble purpose to contribute, its findings should be read with three limitations. First, as two of the researchers possessed intimate knowledge of the institution under study, it was a challenge to completely avoid information bias. Their own experience, relationship with the interviewees and the interpretation of the information, provided some challenges throughout the research. Despite this, however, the inclusion of other co-authors not affiliated with the institution has neutralized possible biasness.

Second, researchers' relationship with organizational members and their approach to interview them created a tendency among interviewees to perceive that researchers as insiders are well aware of the practices and the culture at the institution and they (the interviewees) were only being tested of their knowledge about the institution. As the $\mathrm{HEI}$ was enduring some changes where reorganization of the staff had recently taken place, researchers observed some degree of uncertainty to participate in the research as one staff member declared "Maybe I need to get my manager's permission to participate in the interview". However, by providing clear information of the research aims and objectives to the interviewees this limitation was overcome.

Finally, the $\mathrm{HEI}$ is only one of some thirty higher education providers in Kosovo. Hence, the current study may not be a representative of all SAP practices in all HEls in the country. The findings therefore provide an introduction to general strategy practices and impact of organizational culture among HEls and within this $\mathrm{HEI}$ in particular.

\section{Ethical Considerations}

As Strategy as Practice deals mostly with strategy, the study was exposed to highly confidential documents. Access to information was provided based on mutual trust and potential benefits to be received from the research. Researchers of this SAP research complied with the demand to be honest in the study. Researchers were well aware of ethical considerations and have ensured the institution that the information shared is held confidential and findings are presented in their original form.

\section{Conclusion}

The underpinning aim of the Strategy as Practice was to focus more on the practices of strategy making rather than treating strategy as a property of an organization. In contrast to the traditional 
view which holds strategy as something organizations have, SAP considers strategy as what organizational members-strategists do. Since its inception, SAP has triggered great interest among various researchers, academics and practitioners.

Qualitative data are a central requirement for developing the Strategy as Practice perspective through observation and experience analysing Strategy as Practice at an HEI operating in Kosovo. The study drew on researchers' own experience, interviews and multiple secondary sources.

Findings of the study suggest that the traditional approach of strategy as an organizational property remains dominant at the $\mathrm{HEl}$; top management is the main body responsible for strategy making while other practitioners shape the strategy practices mainly through their implementation. Culture was observed to play a major role in strategy making process; hence practitioners were involved mainly in implementation of strategies rather than in the making of strategy. With the replacement of management, the $\mathrm{HEI}$ has built a more hierarchical type of organizational culture which poses controversial strategy practices for the future. Nevertheless, the HEl through its strategy practices is successfully retaining its reputation and image in the education sector while attracting new students and elite staff members.

\section{Acknowledgment}

We are indebted to the founding member of the HEI for his permission to carry out the research at the institution and for the continuous courage, motivation and support throughout the research. We thank key personnel of the HEl who provided us with all necessary information. We also thank all interviewees for their cooperation to take part in the study.

\section{References}

Baeta, O., Brito, M. \& Souza, R. (2014).Strategy as Discursive Practice in a Brazilian Public University: A look under the Perspective of Critical Discourse Analysis. Research Gate.

Bailey, A. \& Nagwenyama, O. (2013). Interrogating the Concept of Strategy as Practice in the Context of Information Technology for Development. Proceedings of SIG GlobDev Sixth Annual Workshop.

Boje, D. M. (1991). The Storytelling Organization: A Study of Story Performance in an Office-Supply Firm. Administrative Science Quarterly, 36 (1), 106-126.

Bürgi, P. T., Roos J. \& Jacobs, C. (2001). From Metaphor to Practice in the Crafting of Strategy. Imagination Lab Foundation.

Bürgi, P. T. Jacobs, C. D. \& Roos, J. (2005).From Metaphor to Practice in the Crafting of Strategy. Journal of Management Inquiry, 14 (1), 78-94.

Chia, R. \& MacKay, B. (2007). Post-processual Challenges for the Emerging Strategy-as-Practice Perspective: Discovering Strategy in the Logic of Practice. Human Relations. 60 (1), 217-242.

Fento, Ch. \& Langley, A. (2008). Strategy as Practice and the Narrative Turn. Les cahiers de recherche $d u$ GéPS, 2 (6), 2-35.

Feldman, M.S., \& Orlikowski, W.J. (2011). Practicing Theory and Theorizing Practice. Organization Science. 22 (5), 1240-1253.

Fredericks, D. (2003). Strategizing as Lived Experience and Strategists' everyday efforts to shape Strategic Direction. Journal of Management Studies, 40, (1), 141-74.

Gehman, J., Lounsbury, M., \& Greenwood, R. (2016). How Institutions Matter: From the Micro Foundations of Institutional Impacts to the Macro Consequences of Institutional Arrangements. Research in the Sociology of Organizations. 48, 1-34.

Gioia , D \& Chittipeddi, G. (1991). Sense-making and Sense-giving in Strategic Change Initiation. Strategic Management Journal, 12, (6), 433-48.

Heracleous, L. \& Jacobs, C. (2008). Crafting Strategy: The Role of Embodied Metaphors. Long Range Planning. 41, 309-325.

Jarzabkowski, P. (2002). Strategy as Practice: Recursiveness, Adaptation and Strategic Practices-in-Use. Aston Business School Research Institute.

Jarzabkowski, P. (2005). Strategy as Practice-An Activity-Based Approach. SAGE Publications

Jarzabkowski, P., J. Balogun \& D. Seidl. (2007). Strategizing: The challenges of a practice perspective'. Human Relations, 60 (1), 5-27.

Jarzabkowski, P., Kaplan, S., Seidl, D. \& Whittington, R. (2015).On the risk of Studying Practices in Isolation: Linking what, who and how in Strategy Research. Strategic Organization. Scholar One Manuscripts. 
Jarzabkowski , P. \& Seidl, D. (2015). The Role of Meetings in the Social Practice of Strategy. Organization Studies. 29 (11), 1391-1426.

Johnson, G., Langley, A., Melin L. \& Whittington, R. (2007). Strategy as Practice. Research Directions and Resources. Cambridge University Press.

Maia, J.L., Serio, L.C. \& Alvesfllho, L.G. (2015). Almost Two Decades After: A Bibliometric Effort to Map Research on Strategy as Practice using Two Data Sources. European Journal of Economics, Finance and Administrative Sciences. 73, 7-31.

Oakes, L., Townley. B. \& Cooper, D. (1998). Business Planning as Pedagogy: Language and Control in a Changing Institutional Feld". Administrative Science Quarterly. 43, 257-92.

Seidl, D. \& Whittington, R. (2014). Enlarging the Strategy as Practice Research Agenda. Towards Taller and Flatter Ontologies. Organization Studies. 35 (10), 1407-1421.

Vaara, E. \& Whittington, R. (2012). Strategy as Practice: Taking Social Practices Seriously. Academy of Management Annuals.

Varyani, D. \& Khammarah, M. (2010). A Review of Strategy-as-Practice and the Role of Consultants and Middle Managers. Unpublished Master Thesis. Chalmers University of Technology.

Whittington, R. (1996). Strategy as Practice. Strategy at the Leading Edge. New Research and Conference Reports. Elsevier Science.

Whittington, R. (2001).Learning to Strategize: Problems of Practice. SKOPE Research Paper.

Whittington, R. (2003). The Work of Strategizing and Organizing: for a Practice Perspective. Strategic Organization. 1(1), 117-125.

Whittington, R. (2006). Completing the Practice Turn in Strategy Research. Organization Studies. 27(5), 613634 